\title{
ACUTE ELEVATION OF CORONARY VENOUS PRESSURE DOES NOT AFFECT LEFT VENTRICULAR CONTRACTILITY IN THE NORMAL AND STRESSED SWINE HEART: IMPLICATIONS FOR THE FONTAN OPERATION
}

Robert J. M. Klautz, MD, PhD ${ }^{\mathrm{a} *}$

Gerda L. van Rijk-Zwikker, $\mathrm{MD}, \mathrm{PhD}^{\mathrm{b}}$

Paul Steendijk, $\mathrm{PhD}^{\mathrm{a}}$

Jim Wilde, MD $^{\mathrm{a}}$

David F. Teitel, $\mathrm{MD}^{\mathrm{c}}$

Jan Baan, $\mathrm{PhD}^{\mathrm{a}}$
Objective: After the Fontan operation the right atrium and, thus, the coronary sinus are connected to the pulmonary arterial system, which causes the coronary venous pressure to increase. We investigated the acute effects of elevation of coronary venous pressure on baseline hemodynamics, coronary venous flow, and left ventricular contractility. Methods: In acutely instrumented pigs, during complete right heart bypass and during constant cardiac output, pressure in the right atrium, right ventricle, and coronary sinus was altered by a height-adjustable reservoir. At various levels of coronary venous pressure (up to $4 \mathrm{kPa}$ or up to $30 \mathrm{~mm} \mathrm{Hg}$ ), flow from the reservoir was measured and left ventricular hemodynamics and contractility were measured from catheter-derived left ventricular pressure and (conductance) volume data. Contractility of the left ventricle was assessed by the end-systolic pressure-volume relationship derived during an unloading intervention by adjusting the bypass pump speed. Results: Left ventricular end-diastolic pressure increased slightly (about $5 \%$ ) with each kilopascal increase in coronary venous pressure, most likely related to diastolic ventricular interaction. No other changes in hemodynamic parameters occurred. Neither coronary venous flow nor left ventricular contractility was influenced by changes in coronary venous pressure. Imposing myocardial stress with dobutamine, $10 \mu \mathrm{g} / \mathrm{kg}$ per minute, did not change these findings. Conclusion: Increasing coronary venous pressure to $4 \mathrm{kPa}$ in the intact circulation with intact autoregulation does not affect coronary flow or left ventricular contractility. We found no experimental evidence for the usefulness of diversion of the coronary sinus to the left atrium during Fontan-type operations (J Thorac Cardiovasc Surg 1997;114:560-7)
From the Cardiac Physiology Laboratory, Departments of Cardiology ${ }^{\mathrm{a}}$ and Cardiothoracic Surgery, ${ }^{\mathrm{b}}$ University Hospital Leiden, The Netherlands, and Cardiovascular Research Institute, ${ }^{\mathrm{C}}$ University of California, San Francisco, Calif.

This study was made possible by a grant from The Netherlands Heart Foundation (grant 90.293).

Received for publication Dec. 4, 1996; revisions requested Jan. 15, 1997; revisions received April 23, 1997; accepted for publication April 28, 1997.

Address for reprints: Jan Baan, PhD, Cardiac Physiology Laboratory, Department of Cardiology, C5-P University Hospital Leiden, P.O. Box 9600, 2300 RC Leiden, The Netherlands.

${ }^{*}$ Current address: Department of Cardiothoracic Surgery, University Hospital Rotterdam/Dijkzigt, Dr. Molewaterplein 40, 3015 GD Rotterdam, The Netherlands.

Copyright (C) 1997 by Mosby-Year Book, Inc.

$0022-5223 / 97 \$ 5.00+0 \quad \mathbf{1 2 / 1 / 8 2 9 1 9}$
Datients born with one functional ventricle will generally benefit clinically from a Fontan operation. After this operation, systemic venous pressure increases to maintain pulmonary blood flow and thus cardiac output. This increase is associated with an increase in coronary venous pressure, because the classic Fontan operation incorporates the coronary sinus in the venous circulation. Because of putative adverse effects of this increased coronary venous pressure, some surgeons have advocated that flow through the coronary sinus be redirected to the left atrium. ${ }^{1-3}$ The ensuing small arterial desaturation would be offset by the advantages of normal coronary venous pressure.

Several studies have been undertaken to investigate the effects of coronary venous pressure on coronary flow and myocardial perfusion. Most of the 
older studies, undertaken to understand the physiology of the coronary circulation, have shown a negative effect of increased coronary venous pressure on myocardial perfusion. This has led to the hypothesis of a venous waterfall mechanism. However, more recent studies have vastly increased our understanding of coronary physiology, and a venous waterfall mechanism is no longer believed to exist. On the other hand, surprisingly little research has been done on the effects of coronary venous pressure on left ventricular contractility. After all, adequate myocardial perfusion is necessary for adequate myocardial function. In fact, only three such studies have been undertaken. Although they were similar in setup, they have shown contradictory results. A study in $\operatorname{dogs}^{2}$ showed a negative effect of coronary sinus pressure on left ventricular function, whereas one study in sheep ${ }^{4}$ and one in lambs ${ }^{5}$ could not confirm those findings. These previous studies used coronary sinus balloons to increase coronary venous pressure. This technique has an important limitation: it overlooks the fact that coronary venous drainage takes place not only in the coronary sinus but also directly and to a substantial extent into the right atrium and right ventricle by means of thebesian veins. Drainage into the left ventricle occurs to a much lesser degree. Moreover, this noncoronary sinus flow will increase if coronary sinus pressure increases. ${ }^{6}$ We therefore developed a model to increase coronary venous pressure by increasing the pressure in both the right atrium and right ventricle, matching the clinical setting of the Fontan circulation. This made it necessary to bypass the right chambers of the heart and exclude them from the circulation. In this way we could maintain constant pulmonary blood flow and cardiac output and increase the pressure in the right side of the heart by means of a reservoir in a stepwise fashion.

We hypothesized that increasing pressure in the drainage area of the coronary circulation (coronary sinus, right atrium, and right ventricle) under constant cardiac output would adversely affect left ventricular contractility by reducing coronary blood flow. We also investigated whether increased myocardial stress by dobutamine would alter the effect of coronary venous pressure on left ventricular contractility. These questions were investigated in acutely instrumented, open chest, young pigs.

\section{Methods}

Instrumentation. The surgical and experimental procedures used were reviewed and approved by the animal research committee of the Leiden University. Eight young pigs, weighing $28.3 \pm 7.9 \mathrm{~kg}$, were used for this study. Anesthesia was induced and maintained by an intravenous combination of $\alpha$-chloralose $(100 \mathrm{mg} / \mathrm{kg})$ and morphine $(0.1 \mathrm{mg} / \mathrm{kg})$, and the pigs were ventilated throughout the study. The animals were lying on a heating pad to maintain normal rectal temperatures. Both carotid arteries and jugular veins were dissected for arterial and venous access. Both vagal nerves were dissected and cut to prevent vagal stimulation of the heart. Next, the thorax was opened through a midline sternotomy and the pericardium was retracted by stay sutures. Heparin was administered $(3 \mathrm{mg} / \mathrm{kg}$ ) and the pulmonary artery was dissected and cannulated with a regular arterial cannula. The cannula was connected to the "arterial" side of a bypass circuit (described later). A snare was placed around the pulmonary artery proximal to the cannulation site for the purpose of closing off the vessel between the cannula and the pulmonary valve later on. Next, both caval veins were cannulated with adequately sized metal hooked venous cannulas and connected to the "venous" side of the bypass circuit. Immediately thereafter; extracorporeal circulation was started. Once the animals were supported by bypass, snares were placed proximal to the caval cannulas to occlude the caval veins at their entrance into the right atrium later on. Also, the hemiazygos and azygos veins were dissected, ligated, and transected. A large (30F) venous cannula was inserted through the right auricle, through the tricuspid valve, and into the right ventricle. Additional holes in this cannula assured free drainage of blood from both the right atrium and right ventricle. This cannula was connected to a height-adjustable reservoir, which in turn drained into the venous reservoir of the bypass circuit. Finally, the pulmonary artery and caval snares were snugged, resulting in complete isolation of the right side of the heart from the circulation, with only coronary venous blood draining in the right atrium and ventricle and, subsequently, draining through the large cannula into the height-adjustable reservoir.

The bypass circuit was a regular cardiopulmonary bypass system, without an oxygenator. It consisted of a large open venous reservoir with a heat exchanger, which was connected on its input side with the two caval cannulas and which received the overflow of the height-adjustable coronary venous reservoir (homemade). Its output was connected to a roller pump and the arterial cannula in the pulmonary artery. In the arterial tubing an in-line EM flow probe (Skalar, Delft, The Netherlands) was used to measure flow, and thus cardiac output, only for monitoring purposes during the experiment. The speed of the pump was adjusted to maintain normal cardiac output for pigs of this size (experience from the experimental surgery laboratory of our institution: approximately $70 \mathrm{ml} / \mathrm{kg}$ per minute).

So that instantaneous left ventricular volume could be measured, an appropriately sized (7F, 7 to $10 \mathrm{~mm}$ interelectrode distance) dual-field conductance catheter (Webster Labs, Baldwin Park, Calif.) was advanced through one of the carotid sheaths into the left ventricle and connected to a Sigma 5-DF signal-conditioner-processor (CardioDynamics, Leiden, The Netherlands) to convert instantaneous conductance measurements to volume. The dual 
field was set at $0.25 \times$ original field. ${ }^{7}$ Parallel conductance was measured by means of the salt injection technique. ${ }^{8} \mathrm{~A}$ side port of a connector just before the arterial cannula in the pulmonary artery was used as the injection site for the hypertonic saline solution. Left ventricular pressure was measured with a 6F-tip micromanometer (Braun Medical, Best, The Netherlands), which was advanced through the other carotid sheath into the left ventricle. All analog signals were displayed on a paper recorder and screen for continuous monitoring. The left ventricular pressure and total left ventricular volume signals were also displayed on an X-Y oscilloscope for continuous monitoring of pressure-volume loops. All analog signals were digitized with 12-bit accuracy on an IBM-compatible microcomputer, at a sampling rate of $200 \mathrm{~Hz}$, and saved on a hard disk for subsequent analysis.

Study protocol. After completion of the surgical preparation, a 30 -minute period was allowed for the pigs to reach hemodynamic stability. To determine whether increased coronary venous pressure would change left ventricular contractility, we randomly changed coronary venous pressure by adjusting the height of the coronary venous reservoir from 0 to $40 \mathrm{~cm}$ $\mathrm{H}_{2} \mathrm{O}$ (which corresponds to 0 to $30 \mathrm{~mm} \mathrm{Hg}$ or 0 to 4 $\mathrm{kPa}$ ) in an average of seven steps. Right ventricular phasic pressures were about $5 \mathrm{~mm} \mathrm{Hg}$ above and below the set level of the reservoir at the highest level of the reservoir. After reaching a new level of coronary venous pressure, we waited for 15 minutes before taking new measurements. Coronary venous flow was measured by timed collection of the blood draining from the heightadjustable reservoir, which was connected to the right side of the heart. Samples of this same blood were taken for measurement of venous oxygen saturation. Coronary arteriovenous oxygen content difference was calculated from oxygen saturation of arterial and venous blood samples and hemoglobin concentration. Left ventricular contractility was measured from instantaneous left ventricular pressure and volume during an unloading intervention. Unloading of the heart was achieved by decreasing the pump speed in a few seconds. When left ventricular pressure had dropped to at least half its baseline value, the speed of the pump was returned to its original level. The entire unloading intervention did not take more than 20 seconds. From the baseline left ventricular pressure and volume data, several hemodynamic parameters were calculated: heart rate, stroke volume, end-diastolic volume and pressure, end-systolic volume and pressure, stroke work, and maximum rate of pressure rise $\left(\mathrm{dP} / \mathrm{dt}_{\text {max }}\right)$. From the left ventricular pressure-volume loops registered during the unloading intervention, contractility was assessed with the use of three indices: the end-systolic pressure-volume relationship (ESPVR ${ }^{9}$ ), the $\mathrm{dP} / \mathrm{dt}_{\max }-$ end-diastolic volume relationship (dPEDVR ${ }^{10}$ ), and the preload recruitable stroke work (PRSW ${ }^{11}$ ).

To investigate the effect of $\beta$-adrenergic stimulation on the possible influence of coronary venous pressure on left ventricular contractility, we repeated this protocol after the administration of dobutamine, $10 \mu \mathrm{g} / \mathrm{kg}$ per minute. This drug increases coronary perfusion, myocardial oxygen consumption, and contractility.
Calculations. Coronary arteriovenous oxygen content difference was calculated as follows:

$$
\Delta \mathrm{C}_{A v}=\left(\mathrm{O}_{2} \mathrm{Sat}_{a r t}-\mathrm{O}_{2} \mathrm{Sat}_{v e n}\right) \cdot \text { Hemoglobin }(\mathrm{gm} / \mathrm{L}) \cdot 13.6 \text {. }
$$

Baseline hemodynamic variables were calculated from the mean of five to ten beats in each run before an unloading intervention. They include heart rate (determined from the mean R-R interval of the surface electrocardiogram), which varied minimally during the unloading intervention since vagal responses were blocked by vagotomy; stroke volume, which was calculated as the difference between end-diastolic and end-systolic (conductance catheter-derived) volumes; and cardiac output, which was calculated as the product of heart rate and stroke volume (conductance catheter). The $\mathrm{dP} / \mathrm{dt}_{\max }$ was calculated from the first derivative of the left ventricular pressure signal, and stroke work was calculated from the area contained within the pressure volume loop, or $\int \mathrm{PdV}$. Both of these variables were calculated from each heartbeat during the unloading intervention (discussed later).

Contractility was assessed by means of three indices, the end-ejection phase index ESPVR, the preejection phase index dPEDVR, and the ejection phase index PRSW. The ESPVR was calculated from an unloading intervention by first determining, in every heartbeat, end-systole as the point of maximal elastance, ${ }^{9}$ using an iterative technique, ${ }^{12}$ and then regressing end-systolic pressure against end-systolic volume. The slope of this regression line is called end-systolic elastance, or $\mathrm{E}_{\mathrm{es}}$. We calculated the dPEDVR and the PRSW by linearly regressing, respectively, $\mathrm{dP} / \mathrm{dt}_{\max }$ and stroke work against end-diastolic volume of the same beats of the unloading intervention. Each relationship was characterized by a slope; an increase in the slope of these relationships has been shown to represent an increased contractile state. ${ }^{10,11,13}$

Statistical analysis. We analyzed the effects of coronary venous pressure using a multiple linear regression implementation of analysis of variance. ${ }^{14,15}$ Each dependent variable $\mathrm{Y}$ (such as cardiac output and $\mathrm{E}_{\mathrm{es}}$ ) was regressed against coronary venous pressure (CVP) and dummy variables, coding for interanimal variability $(\mathrm{P})$. The regression equation is represented by the following:

$$
\mathrm{Y}=\mathrm{a}_{\mathrm{o}}+\mathrm{a}_{\mathrm{c}} \mathrm{CVP}+\sum_{i=1}^{7} \mathrm{a}_{\mathrm{p}_{\mathrm{i}}} \mathrm{P}_{\mathrm{i}}
$$

where $a_{0}$ is the intercept of the equation, representing the overall mean of the dependent variable, and the $a_{c}$ associated with coronary venous pressure represents the coefficient of the effect of coronary venous pressure on the dependent variable of interest. The interanimal variability $\mathrm{P}_{\mathrm{i}}$ was introduced in the equation for statistical purposes and its value will not be reported.

Inasmuch as contractility was also assessed during increased adrenergic stimulation, we used a new statistical model to include the effect of dobutamine by introducing a new dummy variable in the equation (D), which was assigned a value of 0 for the control state and a value of 1 for the dobutamine state. An interaction term (CVP - D) was also included to represent the possible change in the relation between coronary venous pressure and the de- 
pendent variable when dobutamine was present. The coronary venous pressures were normalized to prevent collinearity. ${ }^{14}$ The new equation is represented by the following:

$$
\mathrm{Y}=\mathrm{a}_{0}+\mathrm{a}_{\mathrm{c}} C V \mathrm{P}^{\prime}+\mathrm{a}_{\mathrm{d}} \mathrm{D}+\mathrm{a}_{\mathrm{cd}} \mathrm{CVP^{ \prime }} \cdot \mathrm{D}+\sum_{i=1}^{7} \mathrm{a}_{\mathrm{p}_{\mathrm{j}}} \mathrm{P}_{\mathrm{i}}
$$

where CVP' is the normalized coronary venous pressure. Results of multiple regression analysis are presented as value \pm standard error of the mean. All other data are presented as mean \pm standard deviation.

\section{Results}

Fig. 1 illustrates the effect of increased coronary venous pressure on contractility and coronary venous flow in a representative pig. Baseline values for some hemodynamic variables are listed in Table I, together with the results of the multiple linear regression analysis of the effect of coronary venous pressure change on each variable. Baseline hemodynamics were normal for the pigs we used. Cardiac output, stroke volume, end-systolic and end-diastolic volume, end-systolic pressure, stroke work, and $\mathrm{dP} / \mathrm{dt}_{\max }$ did not change significantly with increasing coronary venous pressure. Heart rate and end-diastolic pressure, however, did increase significantly with coronary venous pressure. Each kilopascal increase in coronary venous pressure increased heart rate with 4 beats/min and increased end-diastolic pressure by $0.06 \mathrm{kPa}(\sim 6 \%$ of baseline mean, see Table I).

Baseline coronary venous flow was about $4 \%$ of cardiac output, indicating that this venous outflow of the coronary system was a reasonable estimate of myocardial perfusion. Dobutamine doubled coronary flow and myocardial oxygen consumption, without altering the arteriovenous oxygen content difference (Table II). Surprisingly, none of these variables changed with increasing coronary venous pressure, either before or after increasing myocardial stress with dobutamine.

Contractility, assessed by three independent indices, did not change when coronary venous pressure increased (Table II). Dobutamine, however, increased all indices as evidence of the positive inotropic effect of dobutamine. For all indices the interaction between dobutamine and coronary venous pressure turned out to be nonsignificant; in other words, after increasing contractility and myocardial oxygen consumption, there still was no effect of increased coronary venous pressure on left ventricular contractility. This is also exemplified by the data presented in Fig. 1.
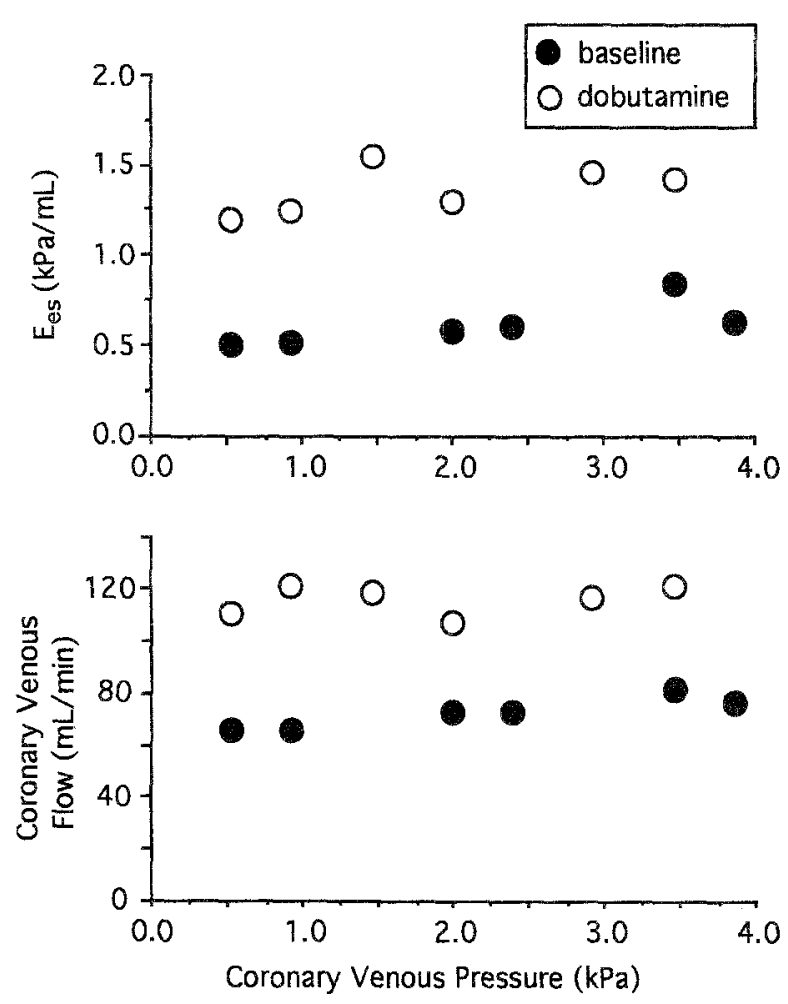

Fig. 1. Contractility, assessed by the slope of the ESPVR $\left(E_{e s}\right)$, and coronary venous flow measured at different levels of coronary venous pressure, before and after the administration of dobutamine, $10 \mu \mathrm{g} / \mathrm{kg}$ per minute, in a representative pig. Neither contractility nor coronary venous flow was affected by coronary venous pressure. Increased cardiac stress by dobutamine increased coronary venous flow and contractility under all circumstances but did not change the lack of correlation with coronary venous pressure.

\section{Discussion}

We have not found any effect of increasing coronary venous pressure from 0 to $4 \mathrm{kPa}(30 \mathrm{~mm} \mathrm{Hg})$ on either left ventricular contractility or coronary venous flow. The only hemodynamic parameters that changed significantly were heart rate and enddiastolic pressure; the others, including end-diastolic volume, did not change significantly. Inducing stress with dobutamine, which doubled myocardial oxygen consumption, did not affect these findings.

Although several studies have addressed the effects of coronary venous pressure on myocardial blood flow, very few have studied the effects on myocardial function. Ilbawi and associates ${ }^{2}$ studied the effects of coronary sinus pressure elevation (by balloon occlusion of the coronary sinus) on myocar- 
Table I. Hemodynamic variables during baseline and changes in coronary venous pressure

\begin{tabular}{|c|c|c|c|c|}
\hline & \multirow{2}{*}{$\begin{array}{c}\text { Baseline } \\
(\text { mean } \pm S D)\end{array}$} & \multicolumn{3}{|c|}{ Multiple linear regression analysis } \\
\hline & & $R$ & Coefficient \pm SEM & $\Delta \% / \triangle C V P_{1 k P a}$ \\
\hline HR (beats/min) & $111.1 \pm 18.1$ & 0.96 & $4.22 \pm 0.73^{*}$ & $+4 \%$ \\
\hline $\mathrm{SV}(\mathrm{ml})$ & $17.8 \pm 4.9$ & 0.85 & $-0.41 \pm 0.36$ & $-2 \%$ \\
\hline $\mathrm{CO}(\mathrm{L} / \mathrm{min})$ & $1.98 \pm 0.61$ & 0.81 & $0.02 \pm 0.05$ & $+1 \%$ \\
\hline $\mathrm{ESV}(\mathrm{ml})$ & $17.8 \pm 8.0$ & 0.64 & $-0.49 \pm 1.00$ & $-3 \%$ \\
\hline $\operatorname{EDV}(\mathrm{ml})$ & $30.6 \pm 10.1$ & 0.64 & $-1.15 \pm 1.28$ & $-4 \%$ \\
\hline $\mathrm{ESP}(\mathrm{kPa})$ & $10.84 \pm 2.31$ & 0.87 & $-0.26 \pm 0.14$ & $-2 \%$ \\
\hline $\mathrm{EDP}(\mathrm{kPa})$ & $1.02 \pm 0.45$ & 0.92 & $0.06 \pm 0.02 *$ & $+6 \%$ \\
\hline $\mathrm{SW}(\mathrm{kPa} \cdot \mathrm{ml})$ & $162 \pm 61$ & 0.86 & $-8.7 \pm 4.6$ & $-5 \%$ \\
\hline $\mathrm{dP} / \mathrm{dt}_{\max }(\mathrm{kPa} / \mathrm{s})$ & $219 \pm 134$ & 0.55 & $-15.8 \pm 8.4$ & $-7 \%$ \\
\hline
\end{tabular}

Baseline means \pm standard deviation (SD) and results of multiple linear regression analysis, where each variable is regressed against coronary venous pressure (in kilopascals) and interanimal variability (see Methods for detailed explanation). $R$, Regression coefficient of each regression analysis; coefficient $\pm S E M$, coefficient and standard error of the mean for coronary venous pressure; the last column gives the predicted change in the variable as a percentage for each kilopascal $(7.5 \mathrm{~mm} \mathrm{Hg}$ ) increase in coronary venous pressure. $H R$, heart rate; $S V$, stroke volume; $C O$, cardiac output; $E S V$, end-systolic volume; $E D V$. end-diastolic volume; $E S P$, end-systolic pressure; $E D P$, end-diastolic pressure; $S W$, stroke work; $d P / d t_{\max }$, maximal first derivative of left ventricular pressure. ${ }^{*} p<0.05$.

dial blood flow and left ventricular function in dogs. They found a significant drop in coronary sinus flow, cardiac index, and left ventricular $\mathrm{dP} / \mathrm{dt}_{\text {max }}$. Unfortunately, they did not correct $\mathrm{dP} / \mathrm{dt}_{\max }$ for the possible and likely change in preload (cardiac index decreased significantly); therefore, it is hard to draw definite conclusions about left ventricular contractility on the basis of the provided information. Moreover, the reported coronary sinus blood flow values (mean $13.5 \mathrm{ml} / \mathrm{min}$ at baseline) are extremely small, suggesting considerable noncoronary sinus drainage (thebesian flow). Increased coronary sinus pressure could drop coronary sinus blood flow by an increase in the thebesian flow. Why cardiac index dropped in Ilbawi's study remains unclear.

Ward, Fisher, and Michael, ${ }^{4}$ studying sheep, used a study design similar to the one used by Ilbawi's group, ${ }^{2}$ but in addition measured myocardial blood flow by radioactive microspheres. They found no change in myocardial blood flow and left ventricular contractility when coronary venous pressure was elevated by balloon occlusion of the coronary sinus. They hypothesized that the difference between their study and Ilbawi's might have been caused by interspecies differences of coronary venous anatomy and thus in the role of thebesian flow. This conclusion is not supported by our findings, inasmuch as we increased the pressure in both the coronary sinus and the right-sided thebesian vessels. Because the thebesian flow into the left ventricle is extremely small $^{6}$ and unlikely to play an important role, we trust that in our study coronary venous pressure was truly elevated. Miura and coworkers ${ }^{5}$ studied isolated lamb hearts and did find a decrease of coro- nary blood flow, but without an effect on ventricular contractility. In this last respect their findings are corroborated by ours.

These studies are the only known studies to have investigated the effects of elevation of coronary sinus pressure on left ventricular contractility. Other studies, however, designed to study the physiology of the coronary circulation, have reported no hemodynamic effects of increased coronary venous pressure. ${ }^{16-21}$ These reports include studies in isolated and intact circulations in dogs and swine. In fact, a decrease in coronary flow, after an increase in coronary venous pressure, was compensated by increased oxygen extraction to maintain oxygen supply in the normal range, whereas no lactate production, as evidence of myocardial hypoxia, was found. ${ }^{16,21}$

An explanation for the small but significant increase in heart rate with increasing coronary venous pressure is most likely a direct effect on the sinus node or an extracardiac effect; as myocardial perfusion and contractility did not change, they cannot be held responsible for this effect. The increase in right atrial pressure and volume leads to atrial and thus sinus node stretch, which has been shown to increase heart rate by virtue of the so-called "Bainbridge" reflex. ${ }^{22,23}$

To explain the increase in end-diastolic pressure, we have to discuss the mechanical effects of increased pressure and volume in the right atrium and ventricle on the left ventricle, as happens in this model when the height-adjustable reservoir is elevated. End-diastolic pressure increased without concomitant increase in end-diastolic volume; in fact, there was a parallel upward shift of the end-diastolic 
Table II. Myocardial oxygen consumption and indices of contractility during baseline; their change with dobutamine infusion and increased coronary venous pressure

\begin{tabular}{|c|c|c|c|c|c|c|}
\hline \multirow[b]{3}{*}{ Dependent variable } & \multirow{3}{*}{$\begin{array}{c}\text { Baseline } \\
(\text { mean } \pm S D)\end{array}$} & \multicolumn{5}{|c|}{ Multiple linear regression analysis } \\
\hline & & \multirow{2}{*}{$\begin{array}{c}R \\
\text { equation }\end{array}$} & \multicolumn{2}{|c|}{ Dobutamine } & \multirow{2}{*}{$\frac{C V P}{C o e f \pm S E M}$} & \multirow{2}{*}{$\frac{\text { Interaction }}{\text { Coef } \pm S E M}$} \\
\hline & & & Coef $\pm S E M$ & \% Change & & \\
\hline $\mathrm{Q}_{\text {cor venous }}(\mathrm{ml} / \mathrm{min})$ & $86.2 \pm 51.5$ & 0.89 & $+83.4 \pm 10.9^{*}$ & $+97 \%$ & $-1.0 \pm 6.0$ & $-11.3 \pm 8.2$ \\
\hline$\Delta \mathrm{C}_{\mathrm{a}-\mathrm{k} \mathrm{O}_{2}}(\mathrm{ml} / \mathrm{L})$ & $75.8 \pm 12.2$ & 0.92 & $-1.8 \pm 2.0$ & $-2 \%$ & $1.1 \pm 1.1$ & $1.6 \pm 1.6$ \\
\hline $\mathrm{MVO}_{2}(\mathrm{ml} / \mathrm{min})$ & $7.8 \pm 4.2$ & 0.90 & $+12.7 \pm 0.7^{*}$ & $+163 \%$ & $0.2 \pm 0.4$ & $0.2 \pm 0.6$ \\
\hline $\mathrm{E}_{\mathrm{es}}(\mathrm{kPa} / \mathrm{ml})$ & $0.62 \pm 0.15$ & 0.76 & $+0.83 \pm 0.11^{*}$ & $+132 \%$ & $-0.00 \pm 0.06$ & $-0.08 \pm 0.09$ \\
\hline dPEDVR $(\mathrm{kPa} / \mathrm{sec} / \mathrm{ml})$ & $5.06 \pm 1.65$ & 0.86 & $+41.82 \pm 3.56^{*}$ & $+826 \%$ & $-1.04 \pm 1.93$ & $1.19 \pm 2.65$ \\
\hline PRSW (kPa) & $8.90 \pm 1.80$ & 0.78 & $+13.62 \pm 1.70^{*}$ & $+153 \%$ & $-0.18 \pm 0.91$ & $1.62 \pm 1.31$ \\
\hline
\end{tabular}

Baseline means \pm standard deviation (SD) and result of multiple linear regression analysis, where each variable is regressed against dobutamine, coronary venous pressure, and interanimal variability (see Methods for detailed explanation). R equation, The regression coefficient for the regression analysis of that dependent variable; the dobutamine coefficient represents the change in the dependent variable after the administration of dobutamine ( $10 \mu \mathrm{g} / \mathrm{kg}$ per minute); $C V P$, coronary venous pressure: this coefficient represents the change in the dependent variable with each kilopascal change in CVP; the interaction coefficient represents the change in the relationship between coronary venous pressure and the dependent variable after dobutamine administration; $Q_{\text {cor venous }}$, coronaty venous flow; $\Delta C_{a \cdot \vee O}$, arteriovenous oxygen content difference; $M V O_{2}$, myocardial oxygen consumption; $E_{e s}$, end-systolic elastance; $d P E D V R$, $\mathrm{d} \mathbf{P} / \mathrm{dt}_{\max }$ - end-diastolic volume relationship; $P R S W$, preload recruitable stroke work.

"p $p<0.05$.

pressure-volume relationship. This implies decreased ventricular distensibility and not altered stiffness. For this reason it is unlikely that the diastolic properties of the left ventricle changed: that would have been reflected by an altered stiffness. The shift in the end-diastolic pressure-volume relationship is more likely caused by an increase in right ventricular volume accompanying the induced increase in right ventricular pressure. ${ }^{24}$ Although we did not find an obvious diastolic dysfunction, it is important to consider the detrimental effects of diastolic dysfunction for the Fontan circulation. In such a circulation, the entire cardiac output is dependent on the balance between the pulmonary vascular resistance and the pressure gradient across that pulmonary vascular bed. Any increase in left ventricular end-diastolic pressure would decrease that gradient and thus cardiac output. It should be emphasized, however, that the increase in enddiastolic pressure we found is inherent to our model, and not caused by the increase in coronary venous pressure, as has been argued earlier.

The mechanical effects of elevated right atrioventricular pressure and volume could also have potential systolic interactive effects. Qualitative information from Weber and colleagues ${ }^{25}$ says that under physiologic circumstances the effect of right ventricular systolic pressure on left ventricular pressure is minimal, unless left ventricular pressure is reduced to hypotensive levels. Quantitatively, systolic gain or cross-talk, calculated as the ratio or percentage of end-systolic elastance of one ventricle versus the other plus the septum, has been reported to be about $15 \%{ }^{26}$ for right-to-left gain and is substantially affected by the absence of the pericardium. ${ }^{27}$ On the basis of this information, large changes in contractility, end-systolic pressure, or stroke volume are unlikely to occur. Indeed, the changes in systolic parameters we found were small and not significant.

Potential limitations of this study. We did not increase the pressure and thus resistance in all the possible coronary venous systems, but only those entering the coronary sinus and right atrium and ventricle, and not the thebesian flow into the left ventricle. We think this is justified for several reasons. First, our study was designed to answer the question whether patients having the Fontan operation have negative contractile effects of increased coronary sinus pressure. In those situations the pressure in the right side of the heart, and not the left side of the heart, is elevated exactly in the same manner as in our study. Second, the thebesian flow to the left ventricle is very small, even under conditions of elevated coronary sinus pressure. ${ }^{6}$ Finally, if left-sided thebesian flow would increase under any circumstance, it would cause a slight arterial desaturation, which did not occur. These considerations also apply to the fact that we measured myocardial perfusion by coronary venous outflow. However, it is possible that regional differences in flow and extraction remained undetected by our methods. We considered them small and unimportant, especially as the right ventricle hardly performed any work.

A second limitation of the study might be that we were not able to simulate the situation of the stressed heart completely: when a patient who has 
had a Fontan operation performs exercise and thus increases systemic venous, right heart, and coronary venous pressures, this condition is only partially mimicked by the administration of dobutamine. ${ }^{28}$ Nevertheless, the dosage that we used did increase contractility ( $\mathrm{E}_{\mathrm{es}}$, dPEDVR, PRSW), coronary flow, and myocardial oxygen consumption substantially, making it unlikely that we should have missed an adverse effect of coronary venous pressure on contractile parameters. In a patient who had had the Fontan operation, who has been subjected to longlasting volume overload and cyanosis, has undergone multiple surgical procedures, and probably has a morphologically inferior ventricle, however, reserves might be much more limited than in these "healthy" pigs.

Finally, it is important to consider the possible long-term effects of elevation of coronary sinus pressure, as mentioned before. Our study has focused on the acute effects of elevation of coronary venous pressure on myocardial function, which are hypothetically mediated by effects on myocardial perfusion and acute congestion. During chronic elevation, other mechanisms may impair ventricular function. These include chronic congestion and myocardial edema, which might alter diastolic filling characteristics and might be detrimental for the patient having the Fontan operation, as has been discussed earlier. These chronic effects need to be addressed either in a long-term model of the Fontan circulation or in a model with chronically elevated coronary sinus pressure; unfortunately, these models are not yet available.

\section{Conclusions}

The present study in intact, acutely instrumented pigs with presumably intact coronary autoregulation has shown no effect of elevation of coronary venous pressure to $4 \mathrm{kPa}$ on hemodynamics, coronary flow, and left ventricular contractility. Increasing myocardial oxygen consumption with dobutamine did not change these findings. Coronary blood flow is not limited by the pressure in the venous part of the coronary circulation, but it seems more likely to be governed by the pressure in the arterial part of the coronary circulation, the intraventricular pressure, and the extensive autoregulatory ability of the coronary vascular bed. These data, therefore, do not support the belief in the desirability to divert the coronary sinus to the left atrium during Fontan-type operations, specifically not for the postoperative phase.
REFERENCES

1. Doty DB, Marvin WJ Jr, Lauer RM. Modified Fontan procedure. J Thorac Cardiovasc Surg 1981;81:470-5.

2. Ilbawi MN, Idriss FS, Muster AJ, DeLeon SY, Berry TE, Duffy $\mathrm{CE}$, et al. Effects of elevated coronary sinus pressure on left ventricular function after the Fontan operation: an experimental and clinical correlation. J Thorac Cardiovase Surg 1986;92:231-7.

3. de Leval M, Kilner P, Gewillig M, Bull C. Total cavopulmonary connection: a logical alternative to atriopulmonary connection for complex Fontan operations-experimental studies and early clinical experience. J Thorac Cardiovasc Surg 1988;96:682-95.

4. Ward KE, Fisher DJ, Michael L. Elevated coronary sinus pressure does not alter myocardial blood flow or left ventricular contractile function in mature sheep: implications after the Fontan operation [see comments]. J Thorac Cardiovasc Surg 1988;95:511-5.

5. Miura T, Hiramatsu T, Forbess JM, Mayer JE Jr. Effects of elevated coronary sinus pressure on coronary blood flow and left ventricular function: implications after the Fontan operation. Circulation 1995;92(Suppl):I1298-303.

6. Scharf SM, Bromberger-Barnea B, Permutt S. Distribution of coronary venous flow. J Appl Physiol 1971;18:924-32.

7. Steendijk P, Van Der Velde ET, Baan J. Left ventricular stroke volume by single and dual excitation of conductance catheter in dogs. Am J Physiol 1993;264:H2198-207.

8. Baan J, Van Der Velde ET, De Bruin HG, Smeenk GJ, Koops J, Van Dijk AD, et al. Continuous measurement of left ventricular volume in animals and humans by conductance catheter. Circulation 1984;70:812-23.

9. Suga H, Sagawa K. Instantaneous pressure-volume relationships and their ratio in the excised, supported canine left ventricle. Circ Res 1974;35:117-26.

10. Little WC. The left ventricular $\mathrm{dP} / \mathrm{dtmax}$-end-diastolic volume relation in closed-chest dogs. Circ Res 1985;56: 808-15.

11. Glower DD, Spratt JA, Snow ND, Kabas JS, Davis JW, Olsen $\mathrm{CO}$, et al. Linearity of the Frank-Starling relationship in the intact heart: the concept of preload recruitable stroke work. Circulation 1985;71:994-1009.

12. Baan J, Van Der Velde ET. Sensitivity of left ventricular endsystolic pressure-volume relation to type of loading intervention in dogs. Circ Res 1988;62:1247-58.

13. Sagawa $K$. The ventricular pressure-volume diagram revisited. Circ Res 1978;43:677-87.

14. Glantz SA, Slinker BK. Primer of applied regression and analysis of variance. New York: McGraw-Hill; 1990.

15. Slinker BK, Glantz SA. Multiple linear regression is a useful alternative to traditional analysis of variance. Am $\mathbf{J}$ Physiol 1988;255:R353-67.

16. Rouleau JR, White M. Effects of coronary sinus pressure elevation on coronary blood flow distribution in dogs with normal preload. Can J Physiol Pharmacol 1985:63:787-97.

17. Pantely GA, Bristow JD, Ladley HD, Anselone CG. Effect of coronary sinus occlusion on coronary flow, resistance, and zero flow pressure during maximum vasodilatation in swine. Cardiovasc Res 1988;22:79-86.

18. Scheel KW, Mass H, Williams SE. Collateral influence on pressure-flow characteristics of coronary circulation. Am $\mathbf{J}$ Physiol 1989;257:H717-25.

19. Scheel KW, Williams SE, Parker JB. Coronary sinus pressure 
has a direct effect on gradient for coronary perfusion. Am J Physiol 1990;258:H1739-44.

20. Farhi ER, Klocke FJ, Mates RE, Kumar K, Judd RM, Canty $\mathrm{JM} \mathrm{Jr}$, et al. Tone-dependent waterfall behavior during venous pressure elevation in isolated canine hearts. Circ Res 1991;68:392-401.

21. Cantin B, Rouleau JR. Myocardial tissue pressure and blood flow during coronary sinus pressure modulation in anesthetized dogs. J AppI Physiol 1992;73:2184-91.

22. Bainbridge FA. The influence of venous filling upon the rate of the heart. J Physiol (Lond) 1915;50:65.

23. Hajdu MA, Cornish KG, Tan W, Panzenbeck MJ, Zucker IH. The interaction of the Bainbridge and Bezold-Jarisch reflexes in the conscious dog. Basic Res Cardiol 1991;86:17585.
24. Janicki JS, Weber KT. The pericardium and ventricular interaction, distensibility and function. Am J Physiol 1980; 238:H494-503.

25. Weber KT, Janicki JS, Shroff S, Fishman AP. Contractile mechanics and interaction of the right and left ventricles. Am J Cardiol 1981;47:686-95.

26. Maughan WL, Sunagawa K, Sagawa K. Ventricular systolic interdependence: volume elastance model in isolated canine hearts. Am J Physiol 1987;H1381-90.

27. Slinker BK, Glantz SA. End-systolic and end-diastolic ventricular interaction. Am J Physiol 1986;251:H1062-75.

28. Mannering D, Cripps T, Leech $G$, Mehta $N$, Valantine $H$, Gilmour S, et al. The dobutamine stress test as an alternative to exercise testing after acute myocardial infarction. $\mathrm{Br}$ Heart J 1988;59:521-6.

\section{Bound volumes available to subscribers}

Bound volumes of The Journal of Thoracic and Cardiovascular Surgery are available to subscribers (only) for the 1997 issues from the Publisher, at a cost of $\$ 110.50$ for domestic, $\$ 139.64$ for Canadian, and $\$ 130.50$ for international subscribers for Vol. 113 (January-June) and Vol. 114 (July-December). Shipping charges are included. Each bound volume contains a subject and author index and all advertising is removed. Copies are shipped within 60 days after publication of the last issue of the volume. The binding is durable buckram with the Journal name, volume number, and year stamped in gold on the spine. Payment must accompany all orders. Contact Mosby-Year Book, Inc., Subscription Services, 11830 Westline Industrial Drive, St. Louis, Missouri 63146-3318, USA; phone $800-453-4351$ or $314-453-4351$.

Subscriptions must be in force to qualify. Bound volumes are not available in place of a regular Journal subscription. 